\title{
A few words on research for graduate students
}

\section{by Fan Chung Graham*}

For graduate students who wish to explore the world of mathematics, here are a few things that you probably would like to know at the beginning of the journey. (I wish someone would have told me so!)

\section{What is research?}

What does research mean? The pursuit of truth? A quest into the unknown?

Well, to start, it means finding a problem and solving it. It could be a tiny step of a small puzzle, (by standing at the shoulder of a giant!). Or, it could also be a glimpse at a bigger picture (eventually). Since any worthwhile problem won't be easy to solve, the road can be long and windy with twists and turns. Nevertheless, here are some factors in your favor:

- It is not a real time game. It is not an exam that you need to turn in within an hour. (Of course, there is an upper bound for the length of your graduate study. Here at UCSD, the bound is 5 years!)

- You are allowed to make mistakes, plenty of them. We all do.

- The percentage of success is not required to be high. In fact, if you can do one research problem out of some large number $(10,100, \ldots)$ of problems, it is good enough.

- You are going to get help from your advisor, friends, professors, other researchers,... You are not alone.

- There are many ways that can help increasing the odds if you keep reading...

\section{For the love of it!}

It is possible to do well only if you really enjoy the process. Find a problem that you have some feeling about.

\footnotetext{
* University of California at San Diego

E-mail: fan@ucsd.edu
}

\section{Getting started}

I often heard, "Math is too big. Wait until I have learned enough."

The fact is that nobody knows everything. Don't wait. Just get started. Try to pick up some problem by talking to your professors. It might also help if you go to seminars or do some reading. Find a favorite problem and sink into it deeply so that it will require you to learn more. In combinatorics, we have the advantage that a lot of problems are easy to state (but often not so easy to solve).

\section{Selection and taste}

As a junior researcher, just try to prove any theorem. If a small result is relevant to several different problems, it has a chance to grow into a bigger result. If you have several interrelated results, it is possible to develop into a theory. Overall, if a problem is fundamental, it will come through in many different areas. On the other hand, good applications help guiding the research toward central problems. The judgement for selection and taste will come later in a natural way.

\section{Depth versus breadth}

A main goal of your graduate study is a Ph. D. thesis. That should be a new and original result that uncovers some mathematical truth. That means you will be the expert in one particular area for which no one knows more than you do. If your expertise can be applied to a few other places, the impact of your work will increase. Some true masters can transplant their depth to a large number of areas. How powerful that can be! So, develop your depth and keep an eye open for the breadth.

\section{Luck or skill}

Luck is for those who are prepared. Be ready when opportunities knock. Erdos liked to say, "My brain is open". Maximize the chance that luck might get 
caught on with you. Especially in combinatorics, we use techniques from many branches of mathematics and beyond. Conversely, combinatorial methods find applications every where. It might help to keep a wide net.

\section{On persistence}

When you work hard on a problem but get stuck, what should you do? Here are a few tips:

- Do not give up easily. A problem proves its worth by fighting back. Have at least some skirmish. Try different ways for looking at the same problem. Test different tools.

- Work on two (or more) problems during the same time period. Maybe you would think on one problem subconsciously when you work on the other probem. When you get stuck on one problem, you can also go back to the other problem.

- You are not alone. Everybody gets stuck most of the time as a matter of fact! Find some related constructive things to do such as reading, going to seminar, finding some different formulation, looking for alternative ways to seeing the problem, etc.

- Talk to a friend or your advisor. When you explain a problem to others, it often gets more clear to you.

- Know when to stop. This is a tricky point. Research is a competition with oneself. If you solve one problem after trying ten, you are doing great. No matter you succeed or not, you learn useful things. When the return diminishes exponentially, it is the time to put it into a folder (so that you can easily get back in again).

\section{You need friends}

You might think that doing research in math is a solo endeavor. Why do you need friends? Well, you find out what is going on from your friends. Your friends are often the best teachers for learning new tricks, tools, techniques, theories, etc. In fact, mathematical research is quite a social activity. The friends that you have made through mathematics are friends for a life time. You see them year after year at various meetings. When you go to any place with a math department, you get friends with common interests. Besides, "peer review" is the way that all mathematical work is evaluated.

\section{Research collaboration}

Why collaborate?

- It is more fun.

- When ideas are bounced around, math gets better.
- The best sources of good problems and new tricks are your coauthors.

- Coauthorship is a closer relationship than friendship. The ultimate situation is when the collaboration evolves into a long term relation, resulting a series of joint-work. That is to be cherished year after year.

What about the division of credit?

- In math, we use the Hardy-Littlewood rule. That is, authors are alphabetically ordered and everyone gets an equal share of credit.

- The one who has worked the most has learned the most and is therefore in the best position to write more papers on the topic.

To do:

- Dig the brain of your advisor who is usually willing to help. Try to befriend at least one faculty each quarter. Apply the same spirit to other graduate students. Prepare something mathematical to say.

- Go to seminars and colloquiums. Talk to departmental visitors and join the lunch/dinner with them.

- Check announcements of meetings/workshops of mathematics and CS societies as well as numerous research centers. Participate at these professional meetings and find out the problems that other researchers are currently working on or interested in.

- Some problems are particularly good for sharing, for example, those with a game flavor or in need of developing concepts. Try to have one such problem for social purposes.

- Pick a problem that you really wish that you alone can solve and then enjoy/endure the frustration in secret.

Not to do:

If you have any bad feeling about sharing the work or the credit, don't collaborate. In mathematics, it is quite okay to do your research independently. (Unlike other areas, you are not obliged to include the person who fund your research.) If the collaboration already has started, the Hardy-Littlewood rule says that it stays a joint work even if the contribution is not of the same proportion. You have a choice of not to collaborate the next time. (If you have many ideas, one paper doesn't matter. If you don't have many ideas, then it really doesn't matter.) You might miss the opportunity for collaboration which can enhance your research and enrich your life. Such opportunity is actually not so easy to cultivate but worths all the efforts involved. 